A 66-year-old woman with a history of subarachnoid haemorrhage was fed for 2 years without complication via a CorfloDual GT percutaneous endoscopic gastrostomy (PEG) (Merck Pharmaceuticals, Inc.). She was admitted with a blockage of her gastrostomy tube, difficulty in infusing feeding formula, and peritubal leakage. Examination revealed an immovable healthy stoma site ("buried bumper syndrome"). Endoscopically, the internal bumper was not discernible on the anterior wall of the stomach. Injection of methylene blue dye allowed visualization of the location and patency of the partially epithelialized fistula. A guide wire was manipulated into the PEG tube, through the fistula, and into the gastric lumen. This was snared and brought out through the mouth. A new PEG was then sited using the standard "pull" method.

Buried bumper syndrome is a rare complication of PEG insertion in which the internal bumper becomes embedded in the gastric or abdominal wall, causing difficulty with feeding, peristomal leakage, pain, and swelling [1]. It occurs in 1.6$6.1 \%$ of cases $[2,3]$ and is thought to result from excessive tension between the internal and external bumpers, causing ischaemic necrosis [4].

Collapse of the gastrostomy tract after migration and epithelialization may lead to endoscopic appearances of a small crevice or a mucosal bulge, but this can be difficult to recognize, as in this case. However, insertion of dye allowed recognition of a persistent fistula. Methylene dye is cheap, safe, and free of the complications that are inherent in the use of contrast radiography and surgery [2-5].

PEG insertion carries risks: wound infections, stomal leaks, and pneumoperitoneum are amongst the commonest sequelae, but perforation, peritonitis, and new fistula formation occur in as many as $5 \%$ of cases [3]. In this case, however, the use of a methylene blue dye injection allowed

\title{
Methylene Blue Dye Injection: an Adjuvant Technique in the Management of Buried Bumper Syndrome?
}

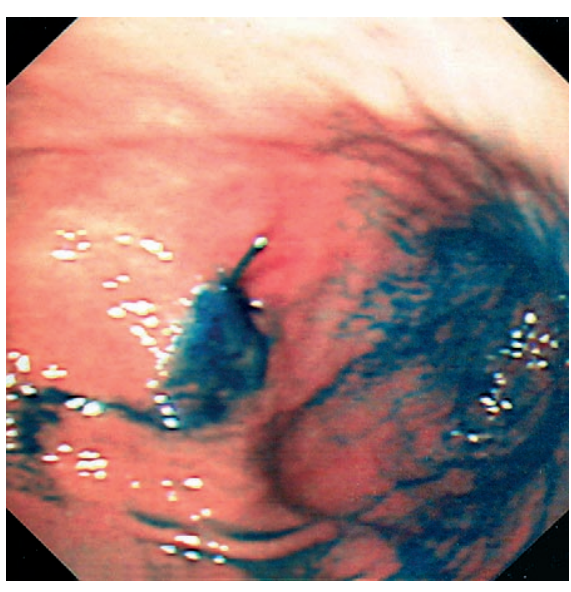

Figure 1 Injection of methylene blue dye allowed visualization of the location and patency of the partially epithelialized fistula, which was initially not visible on endoscopic examination.

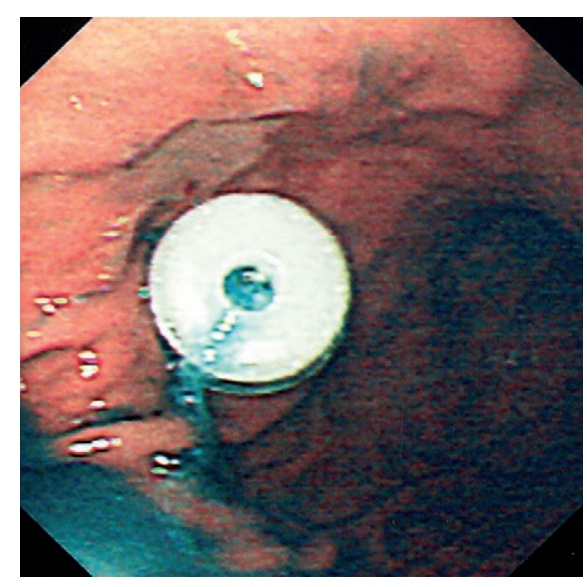

Figure 2 A guide wire was manipulated into the percutaneous endoscopic gastrostomy (PEG) tube, through the fistula, and into the gastric lumen. This was snared and brought out through the mouth. A new PEG was then sited using the standard "pull" method.

continuation of PEG feeding without the risks of a second gastrostomy insertion.

\section{N. Bhala, D. S. Sanders, M. E. McAlindon}

Gastroenterology and Liver Unit, Royal Hallamshire Hospital, Sheffield Teaching Hospitals National Health Service Trust, Sheffield, United Kingdom.

\section{References}

${ }^{1}$ Klein S, Heare BR, Soloway RD. The buried bumper syndrome: a complication of percutaneous endoscopic gastrostomy. Am J Gastroenterol 1990; 85: 448 451

${ }^{2}$ Ma MM, Semlacher EA, Fedorak RN et al. The buried gastrostomy bumper syndrome: prevention and endoscopic approaches to removal. Gastrointest Endosc 1995; 41: $505-508$

${ }^{3}$ Mamel JJ. Percutaneous endoscopic gastrostomy: clinical review. Am J Gastroenterol 1989; 84: $703-710$

${ }^{4}$ Fouch PG, Woods CA, Talbert GA, Sanowski RA. A critical analysis of the Sachs-Vine gastrostomy tube: a review of 120 consecutive procedures. Am J Gastroenterol 1988; 83: 812-815

${ }^{5}$ Rimon E. The safety and feasibility of percutaneous endoscopic gastrostomy placement by a single physician. Endoscopy $2001 ; 33: 241-244$

\section{Corresponding Author}

\section{N. Bhala, MB ChB}

8 Lanesborough Court, Gosforth Newcastle-upon-Tyne NE3 3BZ United Kingdom

Fax: $\quad+441142712692$

E-mail: nijbhala@doctors.org.uk 